\title{
Barriers to Recognition of Erectile Dysfunction Among Diabetic Mexican-American Men
}

\author{
Jobn Zweifler, MD, MPH, Adriana Padilla, $M D$, and Sean Schafer, $M D$
}

Background: Diabetes is widespread among Mexican-Americans, and erectile dysfunction is a wellrecognized complication for which effective treatments are available. Men who desire treatment, however, might not volunteer erectile complaints to their physician, especially across cultural lines.

Methods: We surveyed diabetic Mexican-American men cared for in two community health centers to estimate the prevalence of self-reported erectile dysfunction, to learn how frequently they discuss sexual function with their physician, and to evaluate factors that facilitate or inhibit discussion.

Results: Of the participants surveyed, 59 percent ( 95 percent confidence interval $[\mathrm{CI}]$ 48-70) reported always lacking erection in one or more proposed circumstances, whereas 82 percent ( 95 percent $\mathrm{CI}$ 73-91) reported frequent erectile insufficiency in the same circumstances. Patients reporting erectile problems were no more likely to have discussed sexual function with their physician than those who denied frequent erectile dysfunction. Of those with frequent erectile dysfunction, only 47 percent had had a discussion about sexual function with their physician. We found that these men did not initiate discussion because they were embarrassed or expect the physician to initiate the dialogue.

Conclusions: Erectile dysfunction is common in diabetic Mexican-American men and is underrecognized by clinicians and underreported by patients. Because effective treatments exist, primary care physicians should routinely ask their diabetic patients about erectile function. (J Am Board Fam Pract 1998;11:259-63.)

Family physicians frequently care for patients who have diabetes and its complications. ${ }^{1}$ One common complication in diabetic men is erectile dysfunction, which has been reported in up to 75 percent of diabetic men. ${ }^{2-10}$ Once recognized, erectile dysfunction can be treated with a variety of methods that include vacuum-assisted devices, medications, prosthetic implants, vascular surgery, and behavioral therapy. ${ }^{11-18}$

The key to treating this problem is recognizing it. When patients spontaneously report erectile dysfunction, diagnosis is usually straightforward. Several investigators have shown good correlation between self-reports of sexual dysfunction and objective measures of erectile function. ${ }^{19-23}$ Physicians can also use diagnostic tools such as duplex scanning and nocturnal penile tumescence measurements to quantify physiologic determinants of erectile dysfunction. ${ }^{24}$ Patients are often hesitant to bring up sexual concerns, however. In one study,

Submitted, revised, 30 July 1997.

From the UCSF-Fresno Family Practice Residency Program (JZ, AP, SS), Fresno, California. Address reprint requests to John Zweifler MD, MPH, UCSF-Family Practice Residency Program, 445 South Cedar Ave, Fresno, CA 93702.
97 percent of men reported sexual concerns on a questionnaire, but only 19 percent had discussed these issues with their physician. ${ }^{19}$ Another investigator reported that only 10 percent of patients in a diabetes clinic had ever discussed sexuality with a physician. ${ }^{25}$ If physicians do not inquire and patients do not spontaneously report sexual concerns, then opportunities for improved quality of life can be missed. ${ }^{26}$

In our practice, composed predominantly of Mexican-Americans, we care for many diabetic patients. ${ }^{27}$ Relatively few of our diabetic male patients complain of erectile dysfunction, which is not consistent with the reported prevalence of this problem in similar populations. ${ }^{2-10} \mathrm{We}$ designed a survey to estimate the prevalence of erectile dysfunction in this population and the frequency with which these problems were discussed with the regular physician. We also explored the hypothesis that patients with erectile dysfunction would be more likely to discuss the subject with their physician.

\section{Methods}

The study was conducted at two community health centers located near Fresno, Calif, a major 
Table 1. Health and Demographic Characteristics of Study Patients ( $\mathbf{~ - ~ 8 2 ) . ~}$

\begin{tabular}{lcc}
\hline Characteristic & Median (Range) & Percent \\
\hline Age, $y$ & $56(19-86)$ & \\
Education, y & $1-5$ (none-college) & \\
Duration of diabetes, y & $10(1-37)$ & \\
Language & \\
$\quad$ English & 25 \\
Spanish & 75 \\
Method of glucose control & \\
$\quad$ Diet alone & 12 \\
Oral agent & 48 \\
$\quad$ Insulin & 30 \\
Combination & 10 \\
Hypertension & 53 \\
Alcohol (>2 drinks per week) & 10 \\
Tobacco & 13 \\
\hline
\end{tabular}

Note: Maximum of 3 missing responses or characteristics.

agricultural area. One center is in a suburban site, while the other is in a rural locality. Both serve a large population of Latino (mostly MexicanAmerican) patients, many of whom have low incomes and speak Spanish exclusively.

Using a computer database of discharge diagnoses, we were able to select male patients older than 18 years with Hispanic surnames who were seen at either of the two community health centers for a diagnosis of diabetes mellitus between October 1991 and June 1992. There were $176 \mathrm{pa}-$ tients who met the inclusion criteria.

Two research assistants (1 man, 1 woman, both Mexican-American, Spanish-speaking, collegelevel interns) first tried to contact all prospective patients by mail. Those who responded by returning a signed consent form were telephoned for an interview. The research assistants then tried to telephone those who did not respond to the initial mail inquiry to invite them to participate. Those who indicated an unwillingness to participate were not contacted again.

\section{Questionnaire}

We designed a bilingual questionnaire to obtain demographic and medical information. Questions addressed frequency of erection in four common circumstances. Respondents with self-reported erectile dysfunction were asked to describe any reasons for not discussing sexual function with their physician. Patients were permitted to decline to respond to individual items.
Erectile function was assessed by categorizing the frequency (never, less than 50 percent of time, 50 percent of time, more than 50 percent of time, always) of (1) erection adequate for intercourse, (2) erection upon awakening, (3) erection with visual stimulation, and (4) erection with masturbation. Each participant was also asked whether he had discussed sexual function with his physician. Finally, we asked participants whether the thought of having intercourse ever made them anxious or depressed. Charts were reviewed to verify patient reports of a discussion with the primary physician. Questionnaires were administered by telephone or in person by the research assistants.

\section{Statistics}

We report simple proportions for prevalence of erectile problems with 95 percent confidence intervals calculated by the normal approximation method. We calculated simple odds ratios and 95 percent confidence intervals for the probability of a discussion between the patient and his regular physician about sexual function. Two-tailed $P$ values reported for categorical data were computed using Fisher exact method. Missing responses were excluded for statistical calculations on individual items.

\section{Results}

Of the 176 men who met the inclusion criteria, 69 (39 percent) could not be successfully contacted by mail or telephone, 25 ( 15 percent) declined to participate, and 82 (47 percent) agreed to participate. Seventy-four percent of participants were interviewed by telephone, and the remainder were interviewed in person. Review of medical records corroborated patient reports of discussions about sexual function in 77 percent (61 of 79).

General characteristics of our sample and presence of other health problems known to be related to erectile dysfunction are displayed in Table 1. Among conditions known to be related to erectile dysfunction, hypertension occurred in 53 percent of our sample, tobacco use in 13 percent, and frequent alcohol use in 10 percent.

In Table 2 we display percentages of respondents never capable and those capable less than one half the time of satisfactory erection in the four proposed circumstances. Fifty-nine percent of participants said they never had erections in 
Table 2. Prevalence of Erectile Dysfunction in Study Patients $(n=82)$.

\begin{tabular}{|c|c|c|}
\hline Erectile Function & $\begin{array}{c}\text { Never } \\
\text { Capable } \\
\%(95 \% \mathrm{CI})\end{array}$ & $\begin{array}{c}\text { Capable }<50 \% \\
\text { of Occasions } \\
\%(95 \% \mathrm{CI})\end{array}$ \\
\hline $\begin{array}{l}\text { Erection adequate for } \\
\text { intercourse }\end{array}$ & $20(11-29)$ & $40(28-50)$ \\
\hline Morning erections & $49(29-51)$ & $56(45-67)$ \\
\hline Erection with masturbation & $23(12-34)$ & $44(22-46)$ \\
\hline $\begin{array}{l}\text { Erection with visual } \\
\text { stimulation }\end{array}$ & $33(21-45)$ & $56(44-68)$ \\
\hline One or more of above & $59(48-70)$ & $82(73-91)$ \\
\hline
\end{tabular}

CI - confidence interval.

one or more of the proposed circumstances; 82 percent frequently (more than one half the time) did not have erections in one or more of these circumstances.

In Table 3 are listed the percentages of participants with each erectile problem who reported having discussed erectile function with their physician. Forty-seven percent of patients with frequent occurrence of any of the erectile problems studied had had a discussion with their physician; this rate increased to 58 percent when the problem in question was erections frequently inadequate for intercourse. There were no statistically significant differences in the rate of physician discussion for patients with any of the erectile dysfunctions when compared with those without, although small sample sizes limited statistical power to detect equal or greater differences in the rates of discussion to 5 to 35 percent.

Sixty-one percent of patients with frequent erectile dysfunction who reported feeling depressed about intercourse had spoken to their physician; similarly, 53 percent of patients who reported feeling anxious about intercourse had spoken to their physician. Patients who reported being depressed about intercourse were significantly more likely to have talked with their physician than were those who denied feeling depressed about intercourse (Table 4).

Among patients with frequent erectile dysfunction, most ( 90 percent) had an interest in recciving information about impotence or trying a method to improve erections ( 85 percent). Less than one half of those interested in receiving information (46 percent) or trying a new method (49 percent) had had discussions about this interest with their physician. Figure 1 indicates that lack of specific inquiry on the part of the physician and personal embarrassment were the most common reasons cited by patients with acknowledged erectile complaints for not discussing sexual function with their physician.

\section{Discussion}

We surveyed Mexican-American men with diabetes mellitus to assess the prevalence of self-reported erectile dysfunction and to determine how frequently this dysfunction led to a discussion about the problem with the patient's regular physician. As have previous investigators, ${ }^{4-12}$ we found that erectile dysfunction was common among this diabetic population. We also discovered that despite 85 percent of diabetic men with frequent erectile dysfunction reporting that they would like to try a method for improving erections, remarkably few (at most 58 percent among those with frequent erections inadequate for intercourse) of these patients had had any discussion with their physician about this problem. Although the sample size was too small to draw firm conclusions from the next portion of the analysis, we did not find any statistical evidence that men with frequent erectile dysfunction were more likely than their counterparts without dysfunction to discuss sexual function with their physician. Furthermore,

Table 3. Discussion of Erectile Problems with Physician.

\begin{tabular}{|c|c|c|c|}
\hline \multirow[b]{2}{*}{ Erectile Problem } & \multicolumn{2}{|c|}{ Discussed With Physician } & \multirow[b]{2}{*}{ Odds Ratio } \\
\hline & $\begin{array}{l}\text { Problem Present } \\
\%(n)\end{array}$ & $\begin{array}{c}\text { Problem Absent } \\
\%(n)\end{array}$ & \\
\hline Inadequate for intercourse & $58(33)$ & $38(42)$ & $2.2(0.9-5.5)$ \\
\hline No morning erections & $41(46)$ & $53(30)$ & $0.6(0.2-1.5)$ \\
\hline No erection with masturbation & $46(35)$ & $45(29)$ & $1.0(0.4-2.6)$ \\
\hline No erection with visual stimulation & $48(46)$ & $41(22)$ & $1.3(0.5-3.5)$ \\
\hline Any one or more of the above & $47(66)$ & $36(11)$ & $1.6(4.0-6.0)$ \\
\hline
\end{tabular}

"Problem occurs with $<50 \%$ of occasions.

tProblem occurs with $>50 \%$ of occasions. 
Table 4. Feelings About Sexual Dysfunction and Discussion With the Physician.

\begin{tabular}{lccc}
\hline Problem With Intercourse & $\begin{array}{c}\text { Discussed With Physician } \\
\%(\mathrm{n})\end{array}$ & $\begin{array}{c}\text { Odds Ratio } \\
(95 \% \text { CI })\end{array}$ & $P$ Value \\
\hline Anxious & $53(38)$ & & $1.7(0.6-4.5)$ \\
Not anxious & $39(28)$ & $3.0(1.1-8.1)$ & 0.21 \\
Depressed & $61(33)$ & 0.05 \\
Not depressed & $33(33)$ & & 0 \\
\hline
\end{tabular}

our findings suggest patients believe these discussions often do not take place because physicians do not ask about sexual dysfunction and because the patients fear embarrassment.

The association between self-reported depression and an increased likelihood of discussing erectile problems with the physician merits further study. Exploring patient attitudes about erectile function might help sort out which patients will benefit from treatment for erectile dysfunction.

We had a relatively low response rate $(45$ percent) among the patients originally selected through the database. We believe we were unable to contact many possible participants because the population in large part consisted of itinerant laborers in a predominantly agricultural area. This low response rate could have contributed to response bias in our estimates of prevalence of erectile dysfunction among our patients if the patients whom we were unable to contact had higher rates of erectile dysfunction. Such issues as alcoholism or marital estrangement could have made nonresponders more difficult to contact and might also be related to diminished sexual function. Conversely, nonresponders might have had lower rates

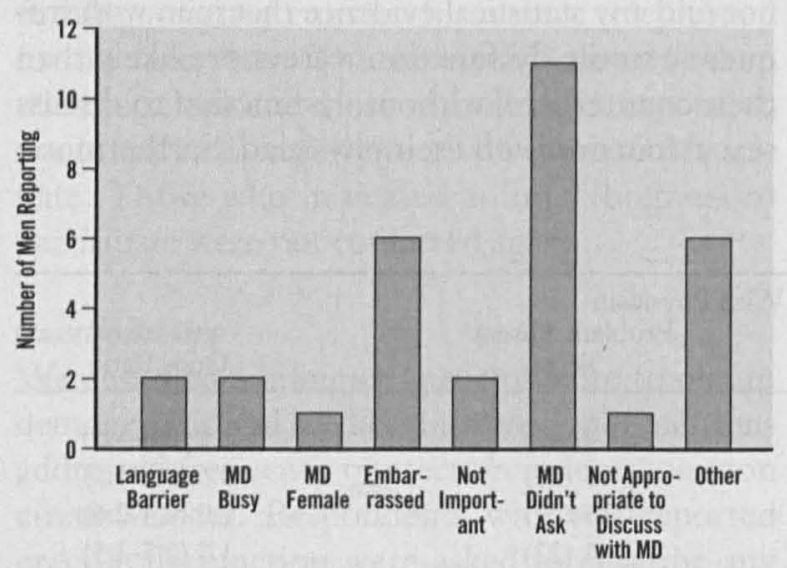

Figure 1. Why diabetic men do not discuss erectile dysfunction with their physician. Respondents invited to list all applicable reasons; 31 total responses. of erectile dysfunction and declined to participate because they were in good health and perceived less potential for personal benefit from participation. We have no reason to believe, however, that discussion about sexual function with the family physician would have been more likely among nonresponders.

We recognize that to generalize our findings to populations of diabetic men of different ages and different ethnic and cultural backgrounds might not be appropriate. Also, we did not survey the ages, language fluencies, training, and ethnicity of the physicians providing care for the patients in the study. Each of these factors probably affects the likelihood that a patient will discuss a topic such as erectile function with his physician.

Clinicians caring for diabetic patients are expected to monitor complications, including retinopathy, nephropathy, neuropathy, and foot pathology. Given the widespread occurrence of impotence in this population, it would be reasonable to screen systematically for impotence as well. Improved surveillance of impotence in this at-risk population is consistent with the increasing emphasis on health promotion in the health care delivery system. ${ }^{2}$

Despite limitations our results are consistent with other studies, which found that diabetic men suffer a substantial amount of erectile dysfunction. ${ }^{4-12}$ Our findings are also consistent with those of previous studies ${ }^{1,26}$ that suggest much of this impairment goes undetected by the patients' physicians. We are left to conclude that family physicians miss many opportunities to improve quality of life for men with erectile problems.

\section{References}

1. Gilchrist V, Miller RS, Gillanders WR, Scheid DC, Logue EE, Iverson DC, et al. Does family practice at residency teaching sites reflect community practice? J Fam Pract 1993;37:555-63.

2. Shabsigh R, Fishman IJ, Schum C, Dunn JK. Cigarette smoking and other vascular risk factors in vas- 
culogenic impotence. Urology 1991;38:227-31.

3. Baum $N$, Neiman $M$, Lewis R. Evaluation and treatment of organic impotence in the male with diabetes mellitus. Diabetes Educ 1988;14:123-9.

4. Ellenberg M. Impotence in diabetes: the neurologic factor. Ann Intern Med 1971;75:213-9.

5. Karacan I. Diagnosis of erectile impotence in diabetes mellitus. An objective and specific method. Ann Intern Med 1980;92:334-7.

6. Waxman SG. Pathophysiology of nerve conduction: relation to diabetic neuropathy. Ann Intern Med 1980;92(2 Pt 2):297-301.

7. Whitehead ED, Klyde BJ, Zussman S, Wayne NS, Shinbach K, et al. Male sexual dysfunction and diabetes mellitus. Multidisciplinary approach to diagnosis and management. NY State J Med 1983;83: 1174-9.

8. Broderick GA, Schwartz S. Erectile dysfunction in diabetes. Hosp Pract Off Ed 1991;26:139-42, 147-55.

9. DeLawter DE. Diabetes and impotence. Md Med J 1990;39:683.

10. Lustman PJ, Clouse RE. Relationship of psychiatric illness to impotence in men with diabetes. Diabetes Care 1990;13:893-5.

11. Comfort A, editor. Joy of sex; a Cordon Bleu guide to lovemaking. New York: Simon and Schuster, 1972.

12. Zorgniotti AW, Lefleur RS. Auto-injection of the corpus cavernosum with a vasoactive drug combination for vasculogenic impotence. J Urol 1985;133: 39-41.

13. Morales A, Surridge DH, Marshall PG, Fenemore J. Nonhormonal pharmacological treatment of organic impotence.J Urol 1982;128:45-7.

14. Michal V, Kramar R. Hejhal L. Revascularization procedure of the cavernous bodies. In: Zorgniotti AW, Rossi G. editors. Vasculogenic impotence. Springfield, Ill: Charles C Thomas Publisher, 1980:239-55.

15. Witherington R. Mechanical devices for the treatment of erectile dysfunction. Am Fam Physician 1991;43:1611-20.
16. Fishman IJ. Experience with the Iydroflex penile prosthesis. Semin Urol 1986;4:239-43.

17. Wiles PG. Successful non-invasive management of erectile impotence in diabetic men. $\mathrm{Br}$ Med J Clin Res Ed 1988;296:161-2.

18. NIH Consensus Conference. Impotence. NIH consensus Development. Panel on Impotence. JAMA 1993;270:83-90.

19. Metz ME, Seifert MH Jr. Men's expectations of physicians in sexual health concerns. J Sex Marital Ther 1990;16(2):79-88.

20. Fichten CS, Rothenberg I, Libman E. Sexual self-efficacy scale-erectile functioning. In: Davis CM, Davis SL, Yarber WL, editors. Sexuality-related measures. A compendium. Lake Mills, La: Graphic Publishing, 1988:129-132.

21. Halvorsen JG, Mommsen C, Moriarty JA, Hunter D, Metz M, Lange P. Male sexual impotence: a case study in evaluation and treatment. J Fam Pract 1988;27:583-7, 591-4.

22. Ackerman MD, D'Attilio JP, Antoni MH, Rhamy RK, Weinstein D, Politano VA. Patient-reported erectile dysfunction: a cross-validation study. Arch Sex Behav 1993;22:603-18.

23. Geisser ME, Murray FT, Cohen MS, Shea PJ, Addeo RR. Use of the Florida Sexual History Questionnaire to differentiate primary organic from primary psychogenic impotence. J Androl 1993; 14:298-303.

24. Shvartzman $P$. The role of nocturnal penile tumescence and rigidity monitoring in the evaluation of impotence. J Fam Pract 1994;39:279-82.

25. Jensen SB. Sexual dysfunction in insulin-treated diabetics: a six year follow-up of 101 patients. Arch Sex Behav 1986;15:271-83.

26. Implementing preventive care. US Public Health Service. Am Fam Physician 1994;50:103-8.

27. Raymond CA. Diabetes in Mexican-Americans: pressing problem in a growing population. JAMA 1988;259:1772. 